\title{
2006 : un nouveau départ
}

\section{Bernard Roux}

\section{(2) OpenEdition \\ Journals}

Édition électronique

URL : http://journals.openedition.org/economierurale/569

DOI : $10.4000 /$ economierurale.569

ISSN : 2105-2581

Éditeur

Société Française d'Économie Rurale (SFER)

Édition imprimée

Date de publication : 1 mars 2006

Pagination : 03-05

ISSN : 0013-0559

\section{Référence électronique}

Bernard Roux, « 2006 : un nouveau départ », Économie rurale [En ligne], 291 | Janvier-février 2006, mis en ligne le 05 janvier 2008, consulté le 24 septembre 2020. URL : http://journals.openedition.org/ economierurale/569; DOI : https://doi.org/10.4000/economierurale.569 


\title{
2006 : un nouveau départ
}

\author{
Par Bernard ROUX • Président du Comité de rédaction
}

D ans la précédente livraison d'Économie Rurale (septembre-décembre 2005, $\left.n^{\circ} 289-290\right)$, Egizio Valceschini a annoncé la fin de son mandat de président du Comité de rédaction de la revue. Au terme d'une période de huit années, au cours de laquelle il a animé le Comité et assuré une parution régulière, Économie Rurale est non seulement demeurée la publication de référence qu'elle est depuis toujours mais elle a gagné en reconnaissance et crédibilité.

Garant du contenu scientifique de la revue, le Comité de rédaction a établi des procédures de gestion éditoriale qui assurent rigueur et qualité. Soucieux de la satisfaction que doit y trouver un lectorat varié, il a su apporter, dans la période récente, une enrichissante diversification de ses rubriques.

Le Bureau de la Société Française d'Économie Rurale, en me faisant l'honneur de me confier la présidence de ce Comité, m'a donc chargé de l'animation d'un outil remarquable, une publication dont le rôle est essentiel, bien au-delà du monde de la ruralité et de l'agriculture.

Les acquis sont là. Éditée par une société savante, conduite par son Comité de rédaction, la revue a su tenir un double objectif: d'une part, contribuer aux débats qui traversent le monde réel, en considérant celui-ci dans sa complexité économique, sociale et politique et, d'autre part, diffuser des connaissances scientifiques qu'elle se doit de prendre en compte dans la diversité des approches et des méthodes. Ses trois sous-titres : « Agricultures 》, " Alimentations ", "Territoires ", qui donnent à la revue les contours de son champ thématique et sa structure éditoriale, sont alimentés par un large éventail de collaborations scientifiques.

Garder à cet outil toute sa qualité et s'efforcer de l'adapter et l'enrichir, tel est le défi. Lue par un public diversifié, Économie rurale doit élargir les formes par lesquelles elle s'adresse à ses lecteurs. Si les articles scientifiques évalués avec toute la rigueur nécessaire continueront à alimenter le cœur de la revue, la recherche de nouvelles modalités de transfert de la connaissance et de l'information sera engagée, notamment avec le concours de I'INRA qui appuie et accompagne les efforts de la SFER et d'Économie Rurale.

Dans cette entreprise de dynamisation, le Comité de rédaction, qui est la pièce maîtresse de la revue, jouera tout son rôle. Ses membres issus de la dernière période éditoriale, invités, à ma demande, à exprimer leur éventuel désir de prolonger leur coopération, ont, pour la plupart d'entre eux, donné leur accord. Qu'ils en soient ici remerciés. Quelques nouveaux membres ont par ailleurs intégré le Comité. Comme par le passé, un Comité restreint, en cours de structuration, aura la charge de l'enchaînement et du suivi des opérations qui aboutissent à la production des numéros de la revue.

Pour le travail de secrétariat et de suivi éditorial, une nouvelle équipe $s^{\prime}$ est mise en place. Au secrétariat de la SFER, auprès de Marie Dézert et Nadine Cortaz, la revue compte maintenant sur Sandrine ModicaCorcuff qui apporte son dynamisme à la réalisation de travaux divers et complexes, auparavant assurés en grande partie par Nicole Bauchet qui a accepté avec toute sa générosité de transmettre son savoir-faire.

Dans la période de transition, Egizio Valceschini a parfaitement assuré le passage du témoin, m'instruisant avec patience et efficacité des différentes tâches relevant du Comité et de son président. Joël Priolon, comme membre du Comité restreint antérieur et actuel, s'est investi et continue à s'investir avec tout son dévouement et toute sa compétence pour garantir la continuité de la revue. Économie Rurale est prête pour un nouveau départ. 